\title{
ACTUALISTIC APPROACH TO ESTIMATION OF THE PETROLEUM POTENTIAL OF CERTAIN AREAS OF THE EARTH CRUST
}

\section{• . околовский}

\section{A. P. Sokolovsky}

юменский госуд рственный нефтег зовый университет. г. юмень

лючевые слов : п леогеогр фия; седимент ция; орг нический углерод; скопление нефти; ловушки Key words: paleography; sedimentation; organic carbon; oil accumulation; traps

кту лизм (в геологии) - это метод позн ния исторической геологии путем ср внения ее с р спростр ненными в н стоящее время геологическими процесс ми, в том числе биогеогр фическими, седимент ционными и другими.

отечественной литер туре термин кту лизм толкуется двояко: во-первых - в прошлом действов ли те же процессы, что и в н стоящее время, поэтому зн ния современных геологических процессов можно переносить в прошлое; во-вторых — к к метод, при котором к поним нию прошлого идут от изучения современных процессов.

ервую форму кту лизм сегодня н зыв ют униформизмом. стоки ее н ходят место в $\mathrm{p}$ боте . йелл « сновы геологии» т. 1-3 (1830-1833 гг.). противовес теории к т строф . йелл р звил учение о медленном и непрерывном изменении земной поверхности под влиянием современных геологических ф кторов. 
тор я форм кту лизм основ тельно изложен и р звит в русской и советской геологии . . рх нгельским и . . тр ховым. то не геологическое мировоззрение, метод исследов ния. овременн я форм кту листического метод н иболее подробно p зр бот н в 1945 г. . . тр ховым, счит ющим, что этот метод имеет огр ниченную применяемость к р зным сторон м геологической жизни емли. н вовсе не применим, н пример, к геологическим процесс м, происходящим в глубин х емли, в ч стности к тектоническим и глубинно-м гм тическим. есьм огр ниченно применение метод кту лизм в п леонтологии. динственн я обл сть, в которой этот метод является н иболее эффективным, — это ос дкон копление, породообр зов ние, то есть литология [1].

оскольку нефть к к минер л относится к группе утигенных, обр зов вшихся н месте их н хождения, то, естественно, ос дочные породы (вместилище скоплений нефти) игр ют гл вную роль к к в позн нии генезис нефти, т к и в р спределении ее скоплений по р зрезу. н стоящей $\mathrm{p}$ боте н ми сдел н попытк $\mathrm{p}$ ссмотреть процесс седимент ции с позиции метод кту лизм .

еоретическое предст вление о происхождении нефти и обр зов нии ее скоплений н иболее полно в н стоящее время сформулиров ны в 1967 г. . . ссоевичем в ос дочномигр ционной гипотезе, суть которой сводится к следующему [2]. н ч ле в ос дк х н к плив ется орг ническое вещество в р ссеянном виде ( ), з тем оно подверг ется мет морфизму, генерирующие при этом углеводороды ( ) н чин ют перемещ ться (мигриров ть) в ловушку. ороды, содерж щие , н зыв ются нефтем теринскими, площ ди, с которых они собир ются в ловушку, - нефтесборными.

« ефтян я ловушк »- это ч сть пл ст коллектор , окруженн я сверху и с боков непрониц емыми пород ми, снизу подпир ющ я пл стовыми вод ми. ще всего т кие ловушки приурочены к выступ м дн б ссейн седимент ции и з ним ют его сводовые или склоновые уч стки. н учной литер туре т кие ловушки кл ссифицируются к к пл стовые сводовые или выклинив ющегося тип . снову т ких ловушек з ложил . бих, который, изуч я нефтяные скопления в зерб йдж не, в 1847 г. сформулиров л нтиклин льную гипотезу н хождения з лежей нефти в земной коре. о его мнению, нефть н ходится в пористых пород х под купол ми непрониц емых слоев. т мысль со временем приобрел всеобщее призн ние и позволяет д же в н стоящее время р збурив ть нтиклин льные скл дки в любом регионе, счит я, что в них могут присутствов ть скопления нефти. то же к с ется методов прогноз и поисков, существующих в н стоящее время, то несмотря н их многообр зие они пок не позволяют определять конкретные координ ты прогнозируемой 3 лежи. остепенно они (метод изоконт ктов, геолого-м тем тическ я модель н основе p спозн в ния обр зов, фронт мигр ции, струйн я мигр ция, дифференци льное ул влив ние и т. д.) утр тили пр ктическую зн чимость. место этих методов выр бот н «прием» проведения поисково-р зведочных р бот, сводящийся к следующему. сследуем я территория вн ч ле к ртируется сейсмор зведкой, выявляются положительные структуры, которые почти всегд относятся к перспективным структур м, 3 тем они р збурив ются глубоким скв жин ми. сли т к я скв жин ок зыв ется «пустой», то приступ ют к р збурив нию следующих поднятий. сли в скв жине встреч ется з лежь нефти, то срочно описыв ются условия ее обр зов ния. ще всего т кие условия объясняются мигр цией углеводородов с т к н зыв емых «нефтесборных площ дей».

. . . лещев в 2005 г. приводил т кие д нные. сновные открытия и формиров ние современной ресурсной б зы нефтедобычи в п дной ибири проходили в 1966-1986 гг. [3].

концу этого период н ч льные сумм рные ресурсы были р звед ны н 43,6 \% при буровой изученности $11 \mathrm{м} / \mathrm{kM}^{2}$. Змеры открытых месторождений по ср внению с 1970-1975 гг. уменьшились в 25 р з. 1993 г. по 2001 г. в было открыто 106 нефтяных месторождений со средними 3 п с ми по к тегории $1-1,1$ млн т, с $1+2-3$ млн т. 1991-2003 гг. добыч нефти восполнил сь прирост ми з п сов всего н $9 \%$. риведенные д нные позволили этому исследов телю сдел ть вывод о том, что нефтяной потенци л в п дной ибири в зн чительной мере р звед н. 1966 г. по 1980 г. эффективность поисково-р зведочных р бот н нефть колеб л сь от 8262 (1970 г.) до 3207 (1980 г.) тонн условного топлив н один метр проходки. 1992 г. этот пок з тель ст л сниж ться до 400 тонн, в последующее время он колеб лся от 250 до 50 т/м проходки.

езкое снижение эффективности поисково-р зведочных р бот н нефть и г з в п дной ибири н фоне почти $2 / 3$ еще нере лизов нного потенци л з ст вляет обр тить н это вним ние, з дум ться о сложившейся ситу ции и р зобр ться в причин х, приводящих к т кому результ ту. н лизируя сложившуюся ситу цию, с эффективностью можно предпол г ть, что или мы не умеем иск ть, или непр вильно оценив ем потенци л. оскольку умение иск ть новые з лежи и достоверность оценки потенци л опир ются н существующие теоретические предст вления о происхождении нефти и формиров нии ее скопле- 
ний, то ст новится очевидно, что действующ я в н стоящее время н учно-пр ктическ я методология решения этих з д ч не отвеч ет современным требов ниям эффективно прогнозиров ть и иск ть новые з лежи нефти.

кой же должн быть генетическ я модель обр зов ния нефти и формиров ния ее скоплений? оскольку основным п р метром в процессе нефтеобр зов ния является орг и его количество, то, учитыв я его генезис (фотосинтез), следует обр щ ть вним ние н п леоусловия простир ния фотосинтез в морской среде. современных морях проникновение свет в водную м ссу, при котором протек ет фотосинтез, сост вляет 50-70 м. кие же глубины были в п леоморях юры и мел . оответственно «пышное» р звитие фитобиоценоз (прежде всего бентос ) может протек ть н ук з нных глубин х. пример, для бурых водорослей (л мин рий) оптим льные современные глубины сост вляют всего 4-18 м. 3 ск 3 нного следует, что «полноценный» источник орг в морской (суб кв льной) обст новке не может формиров ться н глубин х ниже 70 м. овременные подводные съемки н глядно демонстрируют, что почти все выступы морского дн до глубины 50 м, по отношению к соседствующим вп дин м, обильно з селены всевозможными з рослями водорослей. ричин одн - ближе к свету. ожно предпол г ть, что некоторые виды фитофлоры могут обит ть и н большей глубине (100 м и более), но в конечном счете из нее будут генериров ться орг меньше, и это ск жется н коэффициенте нефтен сыщенности коллектор .

н стоящее время по вопросу о генезисе нефти существуют р зличные точки зрения (гипотезы). иболее р зр бот н и обоснов н ф ктическими д нными биогенн я гипотез обр зов ния нефти. ефть по этой гипотезе обр зуется з счет орг нических ост тков ( ), p ссеянных в ос дк х. сточником орг нического веществ служ т простейшие орг низмы и водоросли, обит ющие в б ссейне и после отмир ния н к плив ющиеся в ос дк х. се эти виды при жизнедеятельности либо поглощ ют орг, либо к к р стения выр б тыв ют его. сновные вопросы в нефтяной геологии - из чего, где и когд обр зуется нефть? физическом отношении нефть - сложный углеводородный р створ, состоящий из углерод $(85 \%)$, водород $(14 \%)$ и незн чительного количеств гетероэлементов (O, N, S и др.). нефти обн ружено до 50 микроэлементов. сновным и гл вным элементом нефти является углерод. глерод ( ) встреч ется в природе в свободном и связ нном состояниях. ормы элемент рного углерод - лм 3, гр фит, морфный углерод.

природе существует дв вид углерод :

1. « лубинный углерод», который в земной коре встреч ется н больших глубин х в виде к рбидов. громное количество ( 2 ) выделяется при вулк низме. м ет четвертое место после, е и . глерод присутствует в тмосфере енеры $(2-97 \%)$, pс $(2-95 \%)$. питере, турне, р не, ептуне $\left({ }_{4}-\right.$ мет н).

2. тор я р зновидность углерод имеет биогенную природу. сновн я его м сс концентрируется в ос дочных горных пород х — л льцит, доломит ( a $\left.\mathrm{Mg} \mathrm{CO}_{3}\right)$, сидерит $\left(\mathrm{Fe} \mathrm{CO}_{2}\right)$.

осле открытия в 1811 г. . р го оптической ктивности (свойство среды вызыв ть вр щение плоскости проходящего через нее свет ) было уст новлено, что при прохождении свет через углерод глубинного происхождения плоскость повор чив ется влево, через орг - впр во. о всех нефтях, известных в н стоящее время, плоскости поляриз ционного пучк свет вр щ ются впр во, что позволило многим исследов телям сдел ть вывод об орг ническом генезисе нефти. сновным мех низмом воспроизводств орг н пл нете емля является процесс фотосинтез , когд зеленые р стения превр щ ют световую энергию олнц в орг ническое вещество. отосинтез - единственный биологический процесс, который идет с увеличением свободной энергии системы. се ост льные процессы, исключ я хемосинтез, осуществляются 3 счет потенци льной энергии, з п с емой в продукт х.

сходя из этого постул $\mathrm{T}$, можно предпол г ть, что орг появился н н шей пл нете только с появлением р стений, которые обеспечили обр зов ние воды, кислород, в том числе и первой нефти. оскольку процесс обр зов ния орг осуществляется только через фотосинтез, то следует посмотреть н р стительность, к к источник ор, с позиции ее обит ния. ся флор н пл нете емля делится н три группы: н земн я, болотн я и морск я.

рг нический углерод, выр бот нный н земной р стительностью, хоть и с мый зн чительный по количеству, но он после отмир ния р стений почти весь окисляется до 2 , ч сть которого поглощ ется соседними р стениями, ост льн я ч сть уходит в тмосферу, соединяется с вл гой обл ков и в виде угольной кислоты поп д ет в водоемы, обр зуя к рбониты. олотн я р стительность после отмир ния формирует торф, который впоследствии превр щ ется в уголь и ч стично мет н.

орск я р стительность (водоросли, в основном бентос) существует н глубин х, доступных протек нию фотосинтез . ти глубины в современных морях, к к отмеч лось выше, опуск ются до глубины 50-70 м от поверхности воды. ля формиров ния гомогенных м сс 
орг большое зн чение имеют биогенетическ я «продуктивность» водоем и скорость н копления ос дков в нем.

ри объяснении мех низмов обр зов ния нефти следует всегд помнить, что в «живых» орг низм х (р стительные, животные, микробиоорг низмы и т. д.) углеводородных соединений никогд не быв ет. ни появляются только тогд, когд 3 к нчив ется биологическ я жизнь. оответственно и бентос, и пл нктон продуцируют орг в $\mathrm{p}$ зных количеств х. л нктон - p ссеянные формы орг по всей территории седимент ционного 6 ссейн , бентос - гомогенные формы, лок лизов нные н к ких-либо уч стк х, прежде всего н выступ х дн б ссейн, с т кими глубин ми, которые не превыш ют глубины протек ния фотосинтез . ссеянный и гомогенный орг нический углерод ср зу после поп д ния в ос док подверг ется восст новительному процессу. н соединяется с водородом и другими элемент ми, и генерируются углеводороды. о мнению . . естеров , единственным м теринским веществом з лежей является $\quad$ орг, н ходящееся в современном контуре и , мигр ции 3 предел ми нет и не было в прошлом.

торым существенным ф ктором нефтеобр зов ния и особенно нефтен копления является формиров ние коллектор , содерж щего нефть. ефть и г з в земной коре н ходится в пористых пород х, которые н зыв ются коллектор ми. то в основном ос дочного происхождения породы терригенного или к рбон тного типов. этих пород х пористость имеет p зную природу. терригенных пород х пористость гр нулярн я. ем выше ок т нность и отсортиров нность обломочных ч стиц, тем больше объем межзернового простр нств и лучше прониц емость коллектор .

глинистых пород х, которые относятся к группе терригенных, пористость в целом незн чительн я, но в з висимости от степени литифик ции и тектонического р звития региоН они могут иметь трещинов тую пористость.

ороды к рбон тного тип, н к плив вшиеся в р зных п леообст новк х, х р ктеризуются трещинов той, клив жиров нной или к вернозной пористостью.

оллектор м, содерж щим скопления нефти, присущ т кой п р метр, к к прониц емость - это способность пористой породы пропуск ть через себя р зличные флюиды и г зы при н личии переп д д вления.

ким обр зом, если пористость обусловлив ет емкость коллектор , то прониц емость определяет «пропускную» способность коллектор и в конечном счете нефтеотд чу пл ст . орошими коллектор ми являются песч ники. ними, по д нным . . еменович , связ но $58 \%$ мировых р звед нных 3 п сов нефти и примерно $77 \%$ г 3 . рбон тные коллекторы 3 ключ ют $42 \%$ мировых 3 п сов нефти и только $23 \%$ г 3 .

ряду с вышен зв нными коллектор ми имеют место т к н зыв емые «нетр диционные» коллекторы. ним относятся вулк ногенно-ос дочные, мет морфические, вулк ногенные и д же интрузивные породы.

оскольку породы-коллекторы игр ют существенную роль в процессе нефтен копления, то следует кр тко ост новиться н природе их обр зов ния. ерригенного тип коллекторы состоят из обломков пород р зличного р змер и н к плив ются в седимент ционном б ссейне, куд т кие обломки привносятся в виде «твердого сток » рек ми или в результ те бр зивных процессов. с мом б ссейне эти ос дки под воздействием гидродин мических процессов (волнение водной м ссы) и гр вит ции р спределяются по площ ди. иболее крупные обломочные ч стицы н к плив ются н более мелководных уч стк х дн (выступы дн , структурные носы, шельфовые уч стки и т. д.).

о мере увеличения глубины б ссейн уменьш ются и р змеры обломочных ч стиц. оскольку волнение воды пр ктически постоянно, то обломочные ч стицы будут «путешествов ть» до тех пор, пок не выйдут из-под воздействия волн. к формируется литологический ряд ос дков (по . . тр хову) почти в любом седимент ционном б ссейне [5]. результ те, чем сильнее волнение, тем интенсивнее протек ет отсортиров нность терригенных ос дков (естественное шлихов ние).

пляжной зоне, к к пр вило, н к плив ются крупнообл чные ос дки, по мере смещения в сторону открытого б ссейн они будут з мещ ться более тонкозернистыми и глин ми. глубокой ч сти б ссейн н к плив ются ос дки хемогенного тип (известняки).

зложенный мех низм н копления терригенных ос дков однозн чно свидетельствует о том, что в сводовых ч стях выступов дн б ссейн всегд н к плив ются более крупные по p змер м ч стицы, н крыльях и в межструктурных понижениях - более тонкие или глины. оэтому н м предст вляется, что изобр ж ть литологически экр ниров нную ловушку, когд в своде поднятия пок з ны глинистые отношения, н склон х - одновозр стные песч ные коллекторы, совсем не пр вильно.

оллекторы трещинов того и к вернозного типов (в основном к рбон тные породы) по природе своего обр зов ния отлич ются от гр нулярных, прежде всего п леообст новк ми 
н копления известковистых ос дков. о мнению . . тр хов , эти ос дки н к плив ются н больших глубин х, чем терригенные, трещинов т я пористость в них формируется под воздействием тектонических подвижек. оответственно в любом седимент ционном 6 ссейне зоны трещинов той пористости будут простир ться только вдоль зон тектонических подвижек, не по всей территории р спростр нения к рбон тных пород. этой связи могут возникнуть вопросы. ткуд в т ком коллекторе берется нефть? к последняя поп д ет в коллектор?

ретьим ф ктором ос дочно-мигр ционной гипотезы является мигр ция обр зов вшихся углеводородов в ловушку. ложность р ссм трив емого ф ктор состоит в том, что до сих пор ост ется неизвестным, в к ком физико-Химическом состоянии (или это «жив я» нефть, или р створенные в г зе , или водонефтян я эмульсия) якобы перемещ ются по породе. сож лению, к к отмеч ет . евирсен (1970 г.), «удовлетворительного ответ н вопрос о природе мигр ции и ккумуляции нефти в н стоящее время мы не имеем, и в связи с этим следует помнить, что с мого процесс никто и никогд непосредственно н блюд ть не мог. сю информ цию об этом процессе мы получ ем в период р зр ботки з лежи и р знообр зных умозрительных 3 ключений» [6]. Ызв но это, прежде всего, тем, что до сих пор однозн чно не определено, к к формируется исходное для последующей генер ции . ожно предположить, что если р ссеянно по породе к кого-то тел , то, преобр зов вшись, оно ост ется в этой породе в виде . то н глядно видно н примере юрских и меловых отложений п дной ибири. сли же орг ническое вещество н к кихто уч стк х 6 ссейн седимент ции н к плив ется в гомогенной форме (подобно торфу), то обр зуются скопления (з лежь) , которые тоже ост ются н месте («инситу» по . . лицкому), никуд не мигрируя.

н стоящее время большинство исследов телей при объяснении мех низм обр зов ния з лежей отд ют предпочтение процесс м мигр ции. ри этом нет ответов н ряд вопросов. очему нефть поп д ет в коллектор, где есть 3 крыт я пористость, и почему коэффициент извлечения нефти при интенсивном н нее воздействии не превыш ет 35-40 \%? очему больше половины нефти из з лежи не извлек ется? твет н пр шив ется один нефть никуд не мигрирует, «рожд ется»н месте. ледующий вопрос: возможно ли перемещение нефтяной эмульсии по поровому простр нству в условиях ртези нского б ссейн ? гр нулярном коллекторе т кого 6 ссейн вод, подчиняясь з кону гр вит ции, всегд двиг ется только сверху вниз, не н оборот. ефть по этому же з кону двиг ется только снизу вверх. олуч ется, что в очень «тесном» поровом простр нстве, к тому же 3 полненном седимент ционными вод ми, может осуществляться «встречное» движение. чевидно, нет. оэтому все предположения, что может быть струйн я мигр ция, дифференци льное ул влив ние, фронт мигр ции и т. Д., недок зуемы, эксперимент льно никем и нигде не подтверждены.

ми р ссмотрены три основных п р метр , применяемые в н стоящее время при оценке перспектив нефтег зоносности и р зр ботки методов поиск новых з лежей, - это источник орг, н личие коллекторов, являющихся вместилищем 3 лежей, и предпол г емый мех низм формиров ния скоплений - мигр ция . в первых п р метр можно хорошо отслежив ть н современных процесс х ос дкон копления. игр цию проследить пок невозможно. этой связи возник ет вопрос, можно ли современные процессы формиров ния источников орг и коллекторов переносить в прошлое время, и н их основе проводить прогнозиров ние и поиск новых скоплений ? к зыв ется, можно. процессе фотосинтез (поглощение солнечной энергии) хлорофиллом выр б тыв ется орг - гл вный п р метр нефтеобр зов ния.

н стоящее время нефти, выявленные в рифейских отложениях, имеют т кую же оптическую ктивность (вр щение впр во), что и нефти стр тигр фических возр стов (от кембрия до нтропоген ). этой связи можно уверенно предпол г ть, что ф ктор фотосинтез можно использов ть при кту листическом н лизе н копления орг

ормиров ние коллекторов, в первую очередь гр нулярного тип , подчиненно двум физическим процесс м - гидродин мике (волнению) б ссейн седимент ции и з кону гр вит ции. ти процессы всегд существов ли и будут проявлять себя в любом б ссейне, содерж щем воду. оскольку процессы фотосинтез «породили» появление р стительности и воды, то несомненно эти процессы должны н лизиров ться при кту листическом подходе к ним.

к же использов ть кту листический подход к оценке перспектив нефтег зоносности отдельных регионов п дной ибири н фоне резкого снижения эффективности поисковоp зведочных р бот. ри прогнозе новых скоплений нефти следует помнить, что нефти обр зуются и содерж тся в конкретных пл ст х, не в к ких-то толщ х, свит х и т. Д., хотя с ми свиты состоят из пл стов. о этой причине при оценке перспектив и выр ботке конкретных рекоменд ций для пост новки поискового бурения необходимы следующие меро- 
приятия: дет льн я корреляция исследуемого р зрез, выделение и прослежив ние нефтесодерж щих и перспективных пл стов; оконтурив ние гр ниц (б ссейнов) р спростр нения к ждого из этих пл стов; определение п леоморфологии дн $б$ ссейн седимент ции для к ждого исследуемого пл ст ; определение п леоглубины н копления ос дков к ждого пл ст ; построение п леогеогр фической к рты (схемы) б ссейн седимент ции по исследуемому пл сту.

леогеогр фическ я к рт является суммирующим документом при решении прогнозных поисковых $з$ д ч в том или ином регионе. этой к рте должны быть н несены изоб ты п леоглубин. оследние позволяют уст новить оптим льный предел р спростр нения фотосинтез и н копления хороших коллекторов. уч стк х 6 ссейн, оконтуренных изоб т ми 0-70 м, все лок льные поднятия, в ряде случ ев отдельные уч стки шельф , можно относить к к тегориям перспективных. осле т кого н лиз и выполненных геологотектонических построений можно приступ ть к выбору первоочередных объектов для пост новки н них поискового бурения.

о всех учебник х, пособиях и публик циях при р ссмотрении особенностей $\mathrm{p}$ спределения $з$ лежей нефти и г $з$ почти всегд встреч ются т кие понятия, к к «нефтег зоносные резерву ры», «нефтег зоносные комплексы», «нефтег зоносные провинции», «нефтег зоносные р йоны, зоны», пояс нефтен копления и т к д лее. к видно из определений этих понятий, гл вным в их содерж нии является н личие коллектор , по которому могут перемещ ться углеводороды. онятие «мигр ция нефти» порождено ос дочно-мигр ционной гипотезой ее обр зов ния.

сли придержив ться мнения . . лицкого (нефть «инситу»), то ст новится очевидным, что перечисленн я выше «терминология» не игр ет ни к кой роли в процесс х обр зов ния и н копления нефти.

ефть всегд н ходится в конкретном пл сте-коллекторе, который н к плив ется в конкретном седимент ционном б ссейне с присущими ему морфологическими особенностями.

олько п леогр фические обст новки б ссейн седимент ции определяют х р ктер н копления к к с мого коллектор, т к и мест обит ния фитофлоры (в основном бентос ), и формиров ния исходных м сс орг, в последствии генерирующего

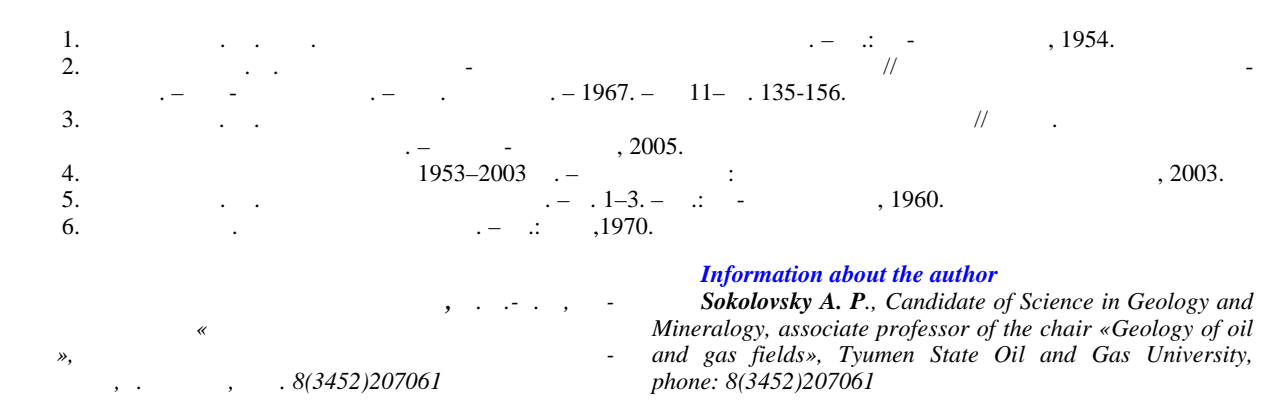

Information about the author

Sokolovsky A. P., Candidate of Science in Geology and Mineralogy, associate professor of the chair «Geology of oil and gas fields», Tyumen State Oil and Gas University, phone: 8(3452)207061 